\title{
Meio de comunicação para surdocegos através da emissão e recepção de sinais sensíveis ao toque
}

RÊDA, R. S.; estudante; Universidade do Estado de Minas Gerais rafaellareda@gmail.com

Orientador: PAGNAN, C. S.; mestre; Universidade do Estado de Minas Gerais

carolinespagnan@gmail.com

CHAVES, M. E. A.; doutora; Universidade Federal de Minas Gerais

mariaemilia.ufmg@gmail.com

BORTOLUS, M. V.; doutor; Universidade Federal de Minas Gerais

bortolus@ufmg.br

Palavras-Chaves: Surdocegueira; comunicação, tecnologia assistiva, design, multidisciplinaridade.

Resumo: A surdocegueira é uma deficiência complexa. Além de apresentar-se em diferentes graus de limitação da audição e da visão do indivíduo, a maneira com que esse percebe sua condição também influencia sua forma de interagir com o mundo. Portanto, o presente estudo buscou desenvolver um dispositivo de comunicação para surdocegos, com o qual pudessem relacionar-se com as pessoas à sua volta de forma autônoma. Inicialmente, a forma do dispositivo seria a de luvas, no entanto, a partir dos testes percebeu-se a necessidade de mudança, a qual deu origem ao formato de teclado. Dentre os principais pontos levantados pela pesquisa, percebe-se a relevância da multidisciplinaridade e do contato direto com os usuários do produto que está sendo desenvolvido.

\section{Introdução}

A surdocegueira é uma condição particular e ainda pouco entendida. Sua particularidade relaciona-se com perdas em dois importantes canais sensoriais: visão e audição (LEME, 2015). Uma múltipla deficiência sensorial representa uma deficiência visual e auditiva associadas a outras condições de comportamento e comprometimento. Muitas vezes outros sistemas também são afetados, como tátil, vestibular (equilíbrio), proprioceptivo (posição corporal), olfativo ou gustativo (MEC, 2006).

Posto que a visão e a audição são os principais canais sensoriais utilizados para estabelecer relação com o mundo, o indivíduo surdocego apresenta grande dificuldade em se desenvolver a partir da percepção do que está em sua volta (LAGATI, 1995). Frente a esse contexto, são necessárias novas pesquisas para ampliar as condições de comunicação do surdocego a fim de proporcionar inclusão social, interação e autonomia para este público.

O projeto "Luvas de Comunicação para Portadores de Deficiências Múltiplas", do Laboratório de Bioengenharia (LABBIO) da Universidade Federal de Minas Gerais (UFMG) foi criado com o objetivo de desenvolver uma tecnologia inovadora que permita o diálogo direto de surdocegos com outras pessoas que apresentem ou não a mesma deficiência.

\section{Métodos}

O projeto pode ser dividido em duas fases principais. A primeira consiste no desenvolvimento do protótipo em forma de luvas e a segunda fase compreende o protótipo no formato

\section{UFPEL}


de teclado. Ambas as fases contou com uma equipe multidisciplinar, dividida em três frentes de trabalho: Linguagem, Design e Software e Hardware. Os membros da frente de Linguagem são responsáveis pelas combinações silábicas e a combinação dos movimentos dos dedos; os de Design são encarregados pela interface usuário-hardware e os de Software e Hardware são responsáveis pelo projeto elétrico e mecânico.

A primeira fase iniciou-se com uma revisão de literatura sobre a surdocegueira. Em paralelo, foram pesquisadas possíveis codificações da língua portuguesa, considerando que seriam utilizadas apenas dez unidades de acionamento, uma para cada dedo. Levando em conta que o acionamento seria por meio da combinação de dedos fletidos, buscou-se alinhar os códigos mais utilizados às formas de acionamento mais ergonômicas. Já a recepção das informações acontece em forma de vibração.

Em seguida, a equipe de Software e Hardware desenvolveu uma base de aplicativo à qual estaria ligada a planilha referente à codificação da linguagem. Então, os membros de Design desenvolveram e, juntamente com os de Software e Hardware, montaram protótipos em forma de luvas com diferentes materiais, como látex, lã, poliamida e neoprene.

O estudo foi aprovado pelo Comitê de Ética em Pesquisa da UFMG. Os pares do protótipo em forma de luvas foram enviados para a Associação Educacional para Múltipla Deficiência (AHIMSA), localizada em São Paulo. Esta instituição busca promover a inclusão social de pessoas com deficiência múltipla sensorial, especialmente surdocegueira. O protótipo foi testado com três surdocegos.

A segunda fase iniciou-se com as análises das informações obtidas a partir dos testes realizados na AHIMSA. A equipe começou então, os estudos para adaptação do que estava sendo desenvolvido para um novo protótipo, cujo formato seria semelhante a um teclado. Para a produção do próximo protótipo foi utilizada a tecnologia de prototipagem rápida, principalmente a impressora ProJet 4500 . Seu funcionamento se dá a partir de um processo de adição de camadas de material polimérico em forma de pó.

Com o protótipo em forma de teclado pronto, começou-se a nova fase de testes com os surdeocegos e dessa vez, contudo, além da AHIMSA, foi feita uma parceria com o Núcleo de Acessibilidade e Inclusão (NAI) da UFMG, que possibilitou os testes serem realizados no LABBIO e fossem guiados também pelos próprios pesquisadores do projeto. Para que houvesse padrão na aplicação dos testes, foi feito um protocolo.

\section{Resultados e discussão}

A parceria com a AHIMSA foi fundamental para a melhoria do projeto, pois com ela foi percebida a importância da aplicação de testes com os surdocegos. Dentre as características levantadas a partir dos testes, a sensibilidade dos surdocegos destacou-se, uma vez que se mostrou determinante para a continuidade da pesquisa. Além disso, as considerações dos surdocegos e da equipe da AHIMSA contribuíram para que houvesse uma análise do proje-

\section{UFPEL}




\section{SULDESIGN CIENTÍFICO 2017}

VIII Suldesign - encontro sul-americano

to, em especial, do formato de luvas apresentado pelo dispositivo. Portanto, foi percebido que o uso das luvas gera pouca mobilidade das mãos, dificultando, por exemplo, que o surdocego segure ou toque outros objetos. Tal questão mostra-se ainda mais relevante quando se leva em consideração que o tato é o maior canal sensorial utilizado pelos surdocegos. Outro aspecto gerado foi o fato de que o rápido acesso ou distanciamento do dispositivo não seria possível, uma vez que se leva um tempo relevante para se calçar e descalçar as luvas.

Como solução dos problemas levantados, estabeleceu-se a substituição das luvas por um teclado. Contudo, para tal alteração, foram necessárias diversas mudanças, dentre essas, vale ressaltar o material utilizado para construção do protótipo e seu meio de produção. 0 neoprene destacou-se entre os demais materiais testados para a confecção das luvas, principalmente por impedir que a vibração propagasse por toda a mão. No entanto, o novo protótipo em forma de teclado foi produzido pela impressora ProJet 4500 e apresentou vantagens como maior proteção do circuito, construção de um produto melhor estruturado e com acabamento, além de tornar a sua montagem mais rápida.

Por fim, outro fato que deixou o estudo mais dinâmico foi a possibilidade de se fazer os testes não apenas na AHIMSA, como também no LABBIO, onde todos os pesquisadores poderiam acompanhar e avaliar a aplicação do trabalho que estava sendo feito. Além disso, com a proximidade eram capazes de modificar com mais agilidade o protótipo, caso fosse apresentado algum problema.

\section{Conclusão}

Conclui-se que apesar dos imprevistos ocorridos durante o processo de pesquisa e de ainda haver muito a ser feito para tornar o dispositivo de comunicação ideal para os surdocegos, o projeto alcançou o objetivo esperado. $O$ estudo permite a identificação de possíveis áreas de pesquisa em tecnologia assistiva, em especial, a serem desenvolvidas para que ocorra amplo convívio social e autonomia de pessoas com múltiplas deficiências.

Por fim, é importante destacar a importância da interação multidisciplinar, não apenas durante o avanço do projeto, como também para o crescimento acadêmico dos alunos envolvidos. Da mesma forma, o contato com os surdocegos foi significativo para o desenvolvimento pessoal, sendo possível aprimorar a percepção do outro e suas limitações.

\section{Agradecimentos}

Os autores agradecem à Financiadora de Estudos e Projetos (FINEP) pelo apoio financeiro, ao pesquisador Bartholomeu Machado Nogueira Amaral (in Memorian) e ao professor Marcos Pinotti Barbosa (in Memorian), os idealizadores deste projeto. 


\section{SULDESIGN CIENTÍFICO 2017}

VIII Suldesign - encontro sul-americano

\section{Referências}

AHIMSA. Disponível em: < http://www.ahimsa.org.br/missao.html>. Acesso em: 17 abr. 2017.

LAGATI, Salvatore. Surdocego ou Surdo-Cego - hífen na terminologia. (Trad.). Laura Lebre Monteiro Ancciloto. Projeto Horizonte Ahimsa. Hilton Perkins, 1995.

LEME, CAROLINA GUERREIRO. O papel do instrutor mediador e o impacto da tecnologia assistiva frente à inclusão de alunos com surdocegueira. 2015.

MINISTÉRIO DA EDUCAÇÃO. Saberes e práticas da inclusão: dificuldades de comunicação e sinalização - surdocegueira/múltipla deficiência sensorial. [4. ed.] / Elaboração profa Fátima Ali Abdalah Abdel Cader Nascimento - UFSC/SP, prof ${ }^{a}$. Shirley Rodrigues Maia - AHIMSA. Brasília: Secretaria de Educação Especial, 2006. 